\title{
Striving to improve care for hypospadias patients
}

\author{
Luis H. Braga, MD, PhD
}

Department of Surgery, Division of Urology, McMaster University, Hamilton, ON, Canada

Cite as: Can Urol Assoc J 2017;11 (1-2Suppl1):S54. http://dx.doi.org/10.5489/cuaj.4422

See related article on page $S 48$.

K eays and Dave have done an outstanding job highlighting the most important technical details and discussing some of the most controversial issues in the hypospadias field.

The severity of hypospadias defects can only be properly assessed at the time of repair, more precisely after penile degloving. This unique aspect of hypospadias will ultimately lead to a multitude of surgical approaches, especially when dealing with proximal hypospadias. The resulting practice variability is worrisome, as it creates inconsistency and limits our ability to compare reported surgical outcomes.

In order to address these shortcomings and promote collaboration between centres, academic pediatric urologists need to start their own prospective databases. This will enable surgeons to standardize the type of information collected, with the ultimate goal of improving care provided to hypospadias patients. Prospective data collection allows for periodic review of outcomes and identification of risk factors for failures, which will lead to practice changes and, subsequently, better clinical results. ${ }^{1}$

We, as Pediatric Urologists of Canada (PUC) members, working in a universal access healthcare system, are in a privileged position to make the necessary changes and accomplish these goals. It does not need to be perfect, we just need to start.

Competing interests: The author reports no competing personal or financial interests.

This paper has been peer-reviewed.

\section{Reference}

1. Snodgrass W, Bush N. TIP hypospadias repair: A pediatric urology indicator operation. J Pediatr Urol 2016;12:11-8. https://doi.org/10.1016/i.jpurol.2015.08.016

Correspondence: Dr. Luis H. Braga, Department of Surgery, Division of Urology, McMaster University, Hamilton, ON, Canada; Ihpbraga@gmail.com 